Atmos. Chem. Phys., 3, 1177-1189, 2003

www.atmos-chem-phys.org/acp/3/1177/

\title{
Atmospheric impact of the 1783-1784 Laki Eruption: Part II Climatic effect of sulphate aerosol
}

\author{
E. J. Highwood ${ }^{1}$ and D. S. Stevenson ${ }^{2}$ \\ ${ }^{1}$ Department of Meteorology, University of Reading, UK \\ ${ }^{2}$ Institute for Meteorology, University of Edinburgh, UK
}

Received: 22 January 2003 - Published in Atmos. Chem. Phys. Discuss.: 21 March 2003

Revised: 3 June 2003 - Accepted: 3 July 2003 - Published: 13 August 2003

\begin{abstract}
The long 1783-1784 eruption of Laki in southern Iceland, was one of the first eruptions to have been linked to an observed climate anomaly, having been held responsible for cold temperatures over much of the Northern Hemisphere in the period 1783-1785. Results from the first climate model simulation of the impact of a similar eruption to that of 1783-1784 are presented. Using sulphate aerosol fields produced in a companion chemical transport model simulation by Stevenson et al. (2003), the radiative forcing and climate response due to the aerosol are calculated here using the Reading Intermediate General Circulation Model (IGCM). The peak Northern Hemisphere mean direct radiative forcing is $-5.5 \mathrm{Wm}^{-2}$ in August 1783. The radiative forcing dies away quickly as the emissions from the volcano decrease; however, a small forcing remains over the Mediterranean until March 1784. There is little forcing in the Southern Hemisphere. There is shown to be an uncertainty of at least $50 \%$ in the direct radiative forcing due to assumptions concerning relative humidity and the sophistication of the radiative transfer code used. The indirect effects of the Laki aerosol are potentially large but essentially unquantifiable at the present time. In the IGCM at least, the aerosol from the eruption produces a climate response that is spatially very variable. The Northern Hemisphere mean temperature anomaly averaged over the whole of the calendar year containing most of the eruption is $-0.21 \mathrm{~K}$, statistically significant at the $95 \%$ level and in reasonable agreement with the available observations of the temperature during 1783 .
\end{abstract}

Correspondence to: E. J. Highwood

(e.j.highwood@reading.ac.uk)

\section{Introduction}

Volcanic eruptions are a major natural source of sulphate aerosols. $\mathrm{SO}_{2}$ emitted by an eruption is rapidly converted to sulphuric acid aerosol. Both Stevenson et al. (2003) and Grainger and Highwood (2003) describe the chemical reactions involved in considerable detail. Some eruptions also emit $\mathrm{H}_{2} \mathrm{~S}$ but the emission data is scarce and in any case it is rapidly oxidised to $\mathrm{SO}_{2}$. Stratospheric aerosol reflects solar radiation back to space causing a negative radiative forcing. It also absorbs some solar radiation, heating the stratosphere where the aerosol is itself present. Finally, aerosol of sufficient diameter can act to some extent like a greenhouse gas, preventing terrestrial radiation from reaching space. This long wave direct radiative forcing is largest when the aerosol is in the region of the tropopause, and is generally smaller than the effect of the aerosol on solar (including both visible and near-IR) radiation on timescales of longer than a few days (e.g. Stenchikov et al., 1998). Thus the predominant effect of volcanic aerosol is an increase in the planetary albedo except for regions in polar night. If a large explosive eruption increases stratospheric aerosol levels, it can have a considerable influence on climate for a period of several years (Minnis et al., 1993). The explosive eruption of Mt. Pinatubo in 1991 produced a global cooling of the surface of a few 10ths of a degree which persisted for about two years after the eruption (Intergovernmental Panel on Climate Change, 1995). This type of relatively long climate perturbation is possible since stratospheric aerosol is generally removed slowly, and perturbations can persist for a year or more. Effusive (or less explosive) eruptions that result only in enhanced tropospheric aerosol are generally thought to be much less likely to impact upon climate, because aerosol here has a lifetime of only a few days, being effectively removed by deposition processes. These emissions are an important part of the natural sulphur budget (Graf et al., 1997) and in some ways their effect on tropospheric 
chemistry can be considered analagous to that of slow, continuous anthropogenic releases. However, if such an effusive volcanic $\mathrm{SO}_{2}$ source is long-lived and sufficiently large, and if the emissions are efficiently oxidised to aerosol (i.e. the emissions occur in the summer hemisphere or the tropics), then the aerosol could perturb the Earth's radiation budget at least while the emissions continue.

Usually, the releases from an individual effusive eruption are too small to allow a specific case study. However, in June 1783, the Icelandic volcano Laki began erupting basalt and releasing $\mathrm{SO}_{2}$. Over the following eight months, an estimated $15 \mathrm{~km}^{3}$ of magma and $122 \mathrm{Tg} \mathrm{SO}$ were emitted, with about $60 \%$ of this released over the first six weeks of the eruption (Thordarson and Self, 2002). A dry fog was recorded over much of Europe during the second half of the year (Stothers, 1996), eventually reaching eastwards across Asia (Renovantz, 1788). Ice core data suggests that there was strong fall-out of aerosols from this eruption over Greenland (e.g. Hammer, 1977; Fiacco et al., 1994), the north-eastern Canadian Arctic (Fisher and Koerner, 1981) and Spitzbergen (Fujii et al., 1990) although estimates of how long the aerosol remained in the atmosphere before being deposited in the ice cores are somewhat contradictory.

There has been much debate over the climatic impact attributable to this eruption. Documentary evidence suggests that the summer of 1783 was warm in Europe at least (Stothers, 1999) with frequent thunderstorms. The July mean temperature as recorded in the Central England Temperature record was $18.8^{\circ} \mathrm{C}$, the highest in the dataset prior to 1981. However, 1976 and 1852 were only $0.1^{\circ} \mathrm{C}$ cooler, suggesting that a volcanic eruption is not the only possible cause of such peaks in the record. Wood (1992) shows warm temperatures across Europe during July 1783 and there are also suggestions of unusually warm temperatures in north America during this time (Sigurdsson, 1982). A dry fog and haze persisted throughout much of the summer across the Northern Hemisphere. Franklin (1785) was the first to suggest that the extremely cold winter of $1783 / 84$ may have been connected to the aftermath of the Laki eruption. In fact, the period 1784-1786 was unusually cold in many places (Wood, 1992). In a study of temperature records after 6 major eruptions in the last 100 years, Angell and Korshover (1985) attributed a cooling of $-0.14^{\circ} \mathrm{C}$ in the Northern Hemisphere annual mean temperature in 1783 (compared to the mean of the 5 years before), to the combined eruption of Laki and Asama, a Japanese eruption also occuring in 1783. Briffa et al. (1998) found changes in tree rings which indicated a Northern Hemisphere mean temperature anomaly of $-0.27^{\circ} \mathrm{C}\left( \pm 0.3^{\circ} \mathrm{C}\right.$ being the $95 \%$ confidence limits of this change). However, Zielinski et al. (1994) assert that Asama probably had little climatic impact based on previous eruptions; perhaps this was because Asama eruptions generally do not release much sulphur (Kohno et al., 1993). This eruption may, however, account for reports of a cold wet summer in Japan during 1783 (Mikami, 1987). Thordarson and
Self (2002) analysed temperature records from Europe and the eastern United States, obtaining a larger cold anomaly (from the 1768-98 mean) of 1.3 to $1.4 \mathrm{~K}$ during the three years following Laki. This anomaly is considerably larger than those from other sources but this may have been due to the relatively small geographic distribution of data used.

Stothers (1999) analysed documentary and temperature evidence for several large eruptions and concluded that the appearance of the warm summer in $1783 / 84$, cold winter in 1783 and cool temperatures over the following two to three years were due to both the immediate effect of aerosol from the eruption and a perturbation of the atmospheric circulation. He also suggested that the cold temperatures led to a famine and plague pandemic across the Middle East. Briffa et al. (1994) found that large anomalies in the density of tree rings, and the implied cold temperatures during summer 1783 were restricted to the Northern part of Alaska and Yukon. They also pointed out that low tree ring density in Scandinavian and possibly Canadian forests may have been influenced by the transport and deposition of acidic debris rather than indicating significantly cold temperatures. Perhaps consistent with reduced summer temperatures is the study of Jacoby and D'Arrigo (1999) which attributed the virtual dying out of the Inuit in Northwest Alaska to climatic impacts of the Laki eruption.

The magnitude of some of the effects attributed to the Laki eruption are large, considering that it is not uniformly agreed that there was much stratospheric injection of aerosol precursor. In particular, it is unclear in many earlier studies whether the phrase "dry fog" applies to stratospheric or tropospheric aerosol. Although Thordarson and Self (2002) suggest that the haze extended to substantial heights $(5-16 \mathrm{~km})$, Grattan and Pyatt (1999) consider that the documentary descriptions of the haze are more consistent with an abundance of gas and aerosol in the lowest layers of the atmosphere. They also concluded that the temperature anomalies experienced in 1783 and 1784 were not significantly cold, taking into account the natural variability of the region. Durand and Grat$\tan$ (1999) demonstrated that the haze had serious health consequences for many European communities. Extensive details of the observations of the haze and coincident temperature anomalies can be found in Thordarson and Self (2002). Previous studies have generally used scarce direct temperature measurements and indirect evidence of temperatures such as ice cores and tree rings to infer the climatic impact of Laki. Apart from problems of calibrating these sources, it is likely that the geographical pattern of any response to the volcanic aerosols would be highly inhomogeneous (Robock, 2000). Data from one region may well be unrepresentative of a wider area, and this may be one reason for the differing views in previous studies.

This study offers a new approach for this eruption, in that the climatic impact of a Laki eruption like that which occurred in 1783-1784 is simulated using a climate model rather than relying on interpretation of scarce data. The 
impact upon the chemical composition of the troposphere resulting from the Laki eruption has been simulated in a companion paper using a 3-D chemistry-transport model Stevenson et al. (2003) (hereafter STE03). The sulphate aerosol distributions from the chemical modelling are used here with the Reading Intermediate General Circulation Model (IGCM) to directly simulate the radiative forcing and climate response due to the direct effect of the sulphate aerosol on radiation. Section 2 describes the distribution of sulphate aerosol produced by the eruption and simulated in STE03, while Sect. 3 describes the climate model used and the experimental design. The radiative forcing and resulting surface temperature changes are presented in Sect. 4 . Section 5 discusses the uncertainties associated with this simulation and quantifies some of them using sensitivity tests.

\section{Sulphate aerosol distributions}

The simulation of sulphur dioxide and sulphate aerosol due to the Laki eruption are described in detail in STE03. For the purposes of this paper we use three different timeseries of monthly mean sulphate aerosol distributions in the year immediately following the eruption, beginning in June 1783. These are the pre-industrial background distribution and two Laki simulations, one resulting from injection of the Laki sulphur dioxide evenly between the surface and approximately $9 \mathrm{~km}$ ("Lo") and the other ("Hi") resulting from the injection of $25 \%$ of the Laki sulphur dioxide between the surface and $3 \mathrm{~km}$ and the remaining $75 \%$ around the tropopause $(9-13 \mathrm{~km})$. The latter case is based on preliminary modelling (S. Self, Pers. Comm., 2002) while the former is designed to give a low bound to the altitude of $\mathrm{SO}_{2}$ emission since most gases are like to be released at the top of the cloud. Sulphate aerosol concentrations showed a dramatic increase over much of the Northern Hemisphere. Peak sulphate concentrations of 1-2 ppbv occurred over much of the summer troposphere polewards of around $50^{\circ} \mathrm{N}$, roughly four times the 1990 value. Mean sulphate lifetimes for the Laki cases were up to 9.1 days, longer than in a 1990 simulation by the same model, due to a larger proportion of the Laki aerosol residing in the upper troposphere and lower stratosphere where loss processes are slower. The eruption impact was essentially limited to the Northern Hemisphere, with a small amount of sulphate transport into the Southern Hemisphere in the lower stratosphere.

The peak sulphate impact occurs in the second and third month of the eruption (July/August). In the lower troposphere the anomaly ceases as soon as the emissions cease in February. At higher levels a small perturbation persists for a few months. Since the stratospheric aerosol is still perturbed after the end of the first year following the start of the eruption, in order to calculate radiative forcing and climate impact in subsequent years without the prohibitive expense of running the CTM simulations for further years, an assumption has been made about the removal of the volcanic aerosol from the stratosphere. In the "Lo" scenario, all the extra aerosol is assumed to have left the atmosphere by the end of May 1784 in accordance with the findings in STE03. In the "Hi" scenario, the data sets have been extended for a further two years using different e-folding times for the removal of stratospheric aerosol. For the second and third years following the start of the eruption, in one case ("Hi/Short") the remaining perturbation is assumed to decay with an e-folding time of 3.6 months as was observed after the Mt. St. Helens eruption in 1980 (another extratropical eruption injecting matter into the upper troposphere and lower stratosphere, Jager and Carnuth, 1987) while in the other ("Hi/Long") the decay time is 10 months as was observed after Pinatubo (Kent and Hansen, 1997).

It is important to remember that the chemical model which produced these aerosol fields was driven in each case by meteorology representative of the 1990s and no attempt was made there or here to recreate the conditions of 1783 as this is currently beyond the capability of the models. The aerosol distributions are therefore likely to be more representative at larger time and space scales (i.e. monthly means and zonal averages) rather than the day to day variations at a local scale immediately after the eruption.

\section{Climate model details and experimental design}

The Reading Intermediate General Circulation Model (IGCM) is based on the spectral primitive equation model of Hoskins and Simmons (1975). A more detailed description of the model is given by Forster et al. (2000). Deliberately simple parameterisations for physical processes such as surface transfer, vertical diffusion, convection and stratiform precipitation have been used to allow the many runs needed to explore a large range of climate forcing scenarios. In order to be able to include the effect of aerosol on both short and longwave radiation, a version of the model using the Morcrette (1990) radiation scheme has been used here. The radiation code (run once a day) uses interpolated monthly averaged climatological ozone (Li and Shine, 1995) and prognostic water vapour.

In this study, the direct effect of aerosols on radiation has been included by interpolating between monthly mean 3-D distributions of sulphate mixing ratios from the STOCHEMEd chemical transport model as described by STE03 and the previous section. The possible impact of the sulphate aerosol on clouds (the indirect forcing) is outside the capability of this model but is considered briefly in Sect. 5.2. The aerosol mixing ratios have been interpolated onto the same vertical grid as the IGCM. Aerosol properties have been derived using Mie scattering for the 2 shortwave regions used in the $\operatorname{IGCM}(0.25$ to $0.68 \mu \mathrm{m}$ and 0.68 to $4.0 \mu \mathrm{m})$. Properties were similarly calculated for the longwave region of the spectrum where the aerosol is assumed to be "grey", i.e. the properties 

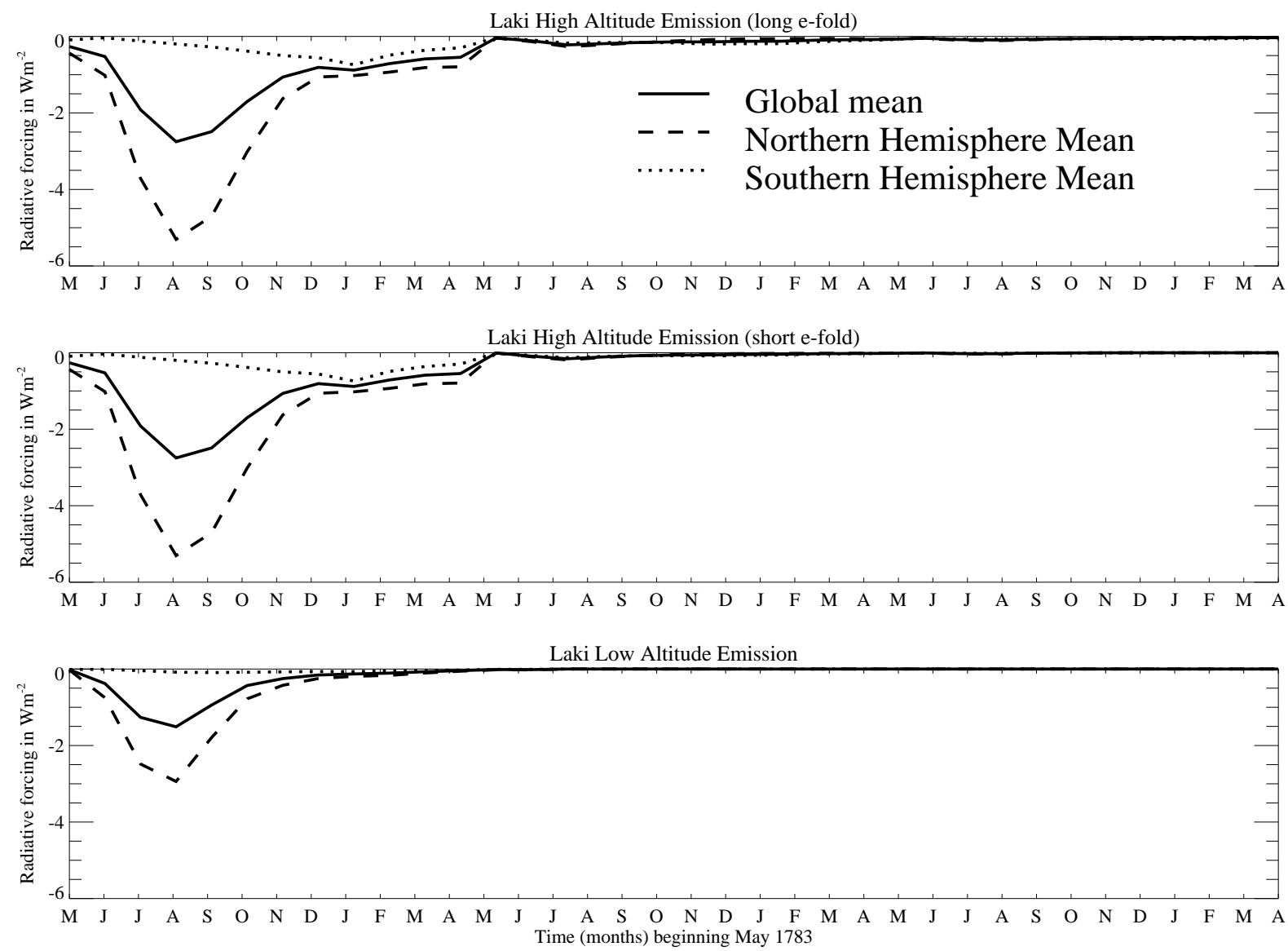

Fig. 1. Time evolution of global and hemispheric mean direct radiative forcing in $\mathrm{Wm}^{-2}$ due to sulphate aerosols from three different simulations of the Laki aerosol cloud. Top panel: Hi/Long, middle panel: Hi/Short, bottom panel: Lo.

are an average over the longwave spectrum. We assume the aerosol is sulphuric acid and the refractive indices for sulphuric acid are taken from WCP (1986). The size distribution depends on whether the aerosol is in the troposphere or stratosphere. In both cases we use a log-normal size distribution; in the troposphere this has mean radius $0.05 \mu \mathrm{m}$ and standard deviation of 2.0 (Kiehl and Briegleb, 1983), while in the stratosphere the distribution has mean radius $0.15 \mu \mathrm{m}$ with standard deviation 1.25 (Stenchikov et al., 1998). For simplicity the aerosols are assumed to be dry. This will be likely to result in an underestimate of the radiative forcing since sulphate aerosols grow and become more effective at scattering solar radiation as the humidity rises (see Sect. 5.1 for further discussion). The aerosol is assigned tropospheric or stratospheric optical properties at each call to the radiation scheme depending on its altitude compared to the climatological tropopause height at that latitude in the IGCM.

In this study the IGCM has been used with 22 levels in the vertical (7 levels in the stratosphere, the top being at $1 \mathrm{mb}$ ), T21 resolution (approximately $6^{\circ}$ by $6^{\circ}$, similar to the resolution used in STE03), and a $100 \mathrm{~m}$ deep mixed layer ocean. The IGCM was spun up using a "clean" or pre-industrial aerosol distribution. The pre-industrial aerosol is produced from emissions of $\mathrm{SO}_{2}$ from natural sources and some anthropogenic biomass burning at $20 \%$ of the 1990 value (see STE03 for more details). A 50 year long control run with the pre-industrial aerosol distribution was then completed to establish a base climatology and ensure no drift. An ensemble of 3 year transient runs was then performed, starting each ensemble member from one of 10 different May 1 states (i.e. 10 different years) from the control simulation. The 3-D Laki aerosol distributions are used for 1 year (June 1783 to May 1784). Subsequently the aerosol used in the IGCM reverts back to the clean pre-industrial distribution for the "Lo" simulation or is scaled acccording to an estimate of the removal rate in the stratosphere for the "Hi/Short" and "Hi/Long" scenarios. In the results section of this paper we describe the ensemble mean difference calculated from the 10 sets of transient runs, each Laki scenario being compared with one with pre-industrial aerosol.

As in the chemical transport model, no attempt is made here to recreate the meteorological conditions of 1783 . Indeed the meteorological conditions used in the IGCM are different to those used to produce the aerosol climatology. 
Laki High Altitude Emission (long e-fold )
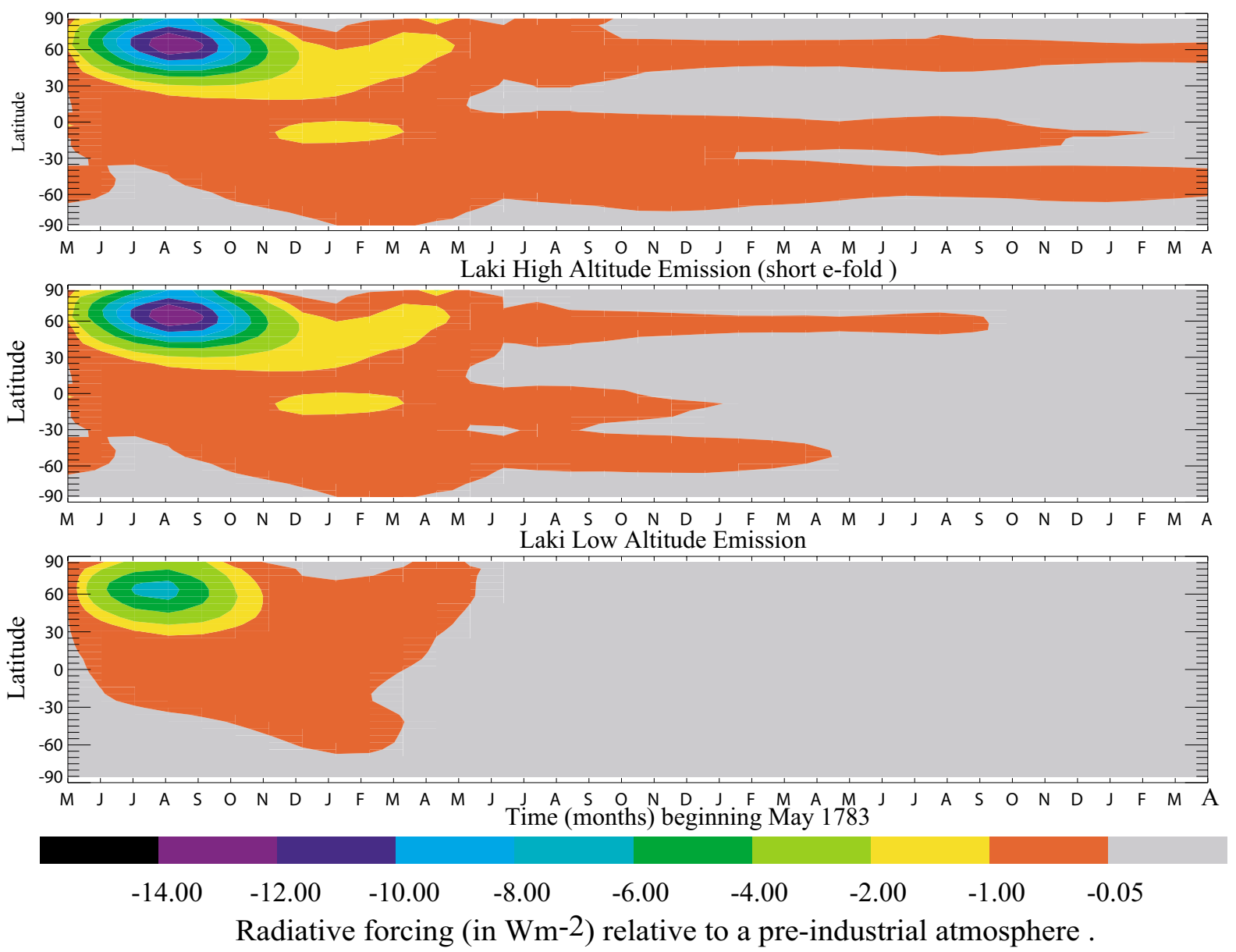

Fig. 2. Time evolution of zonal mean direct radiative forcing in $\mathrm{Wm}^{-2}$ due to sulphate aerosols from simulations of the Laki aerosol cloud. Top panel: Hi/Long, middle panel: Hi/Short, bottom panel: Lo.

However, by imposing the Laki sulphate distributions on a generic representation of climate we can generalise the results of this study to describing how the climate might respond to a Laki-style eruption today, as well as comparing results with the observations from the 1783-1784 eruption.

\section{Results}

\subsection{Radiative forcing}

Radiative forcing is defined here as the change in net radiation at the top of the atmosphere on adding the aerosol from the Laki eruption after stratospheric temperature adjustment. It is calculated off-line using the same radiative transfer scheme and grid as the IGCM. Monthly climatologies of all meteorological parameters are produced from the clean atmosphere runs and these are then used as input to the radiation scheme, since everything but the aerosol must remain fixed to calculate the radiative forcing. The fixed dynami- cal heating approximation was used to bring the stratosphere back into equilibrium when calculating radiative forcing, although in fact for this type of forcing the adjustment should, and does, have very little impact. We consider here the direct component of shortwave radiative forcing, i.e. that which is due to the scattering of solar radiation by the sulphate particles, and the longwave radiative forcing due to the higher altitude and larger magnitude aerosol which can behave similarly to a greenhouse gas.

Figure 1 shows the temporal variation of global and hemispheric mean radiative forcing for all 3 "Laki" aerosol distribution scenarios. Both the global mean and the Northern Hemisphere mean show large radiative forcings during June, July and August 1783, while the Southern Hemisphere mean forcing is much smaller throughout the eruption.

A clear difference can be seen between the "Hi" and "Lo" scenarios in all three means. The peak global mean value was around $-3 \mathrm{Wm}^{-2}$ under the "Hi" scenario and $-1.5 \mathrm{Wm}^{-2}$ under the 'Lo' scenario. Comparatively, the global mean 
a) High Altitude Emission, July 1783

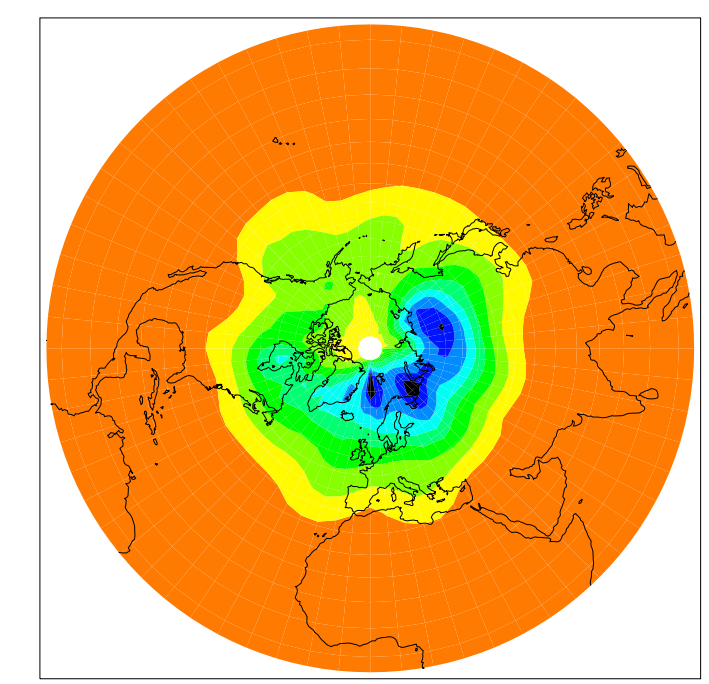

b) Low Altitude Emission, July 1783

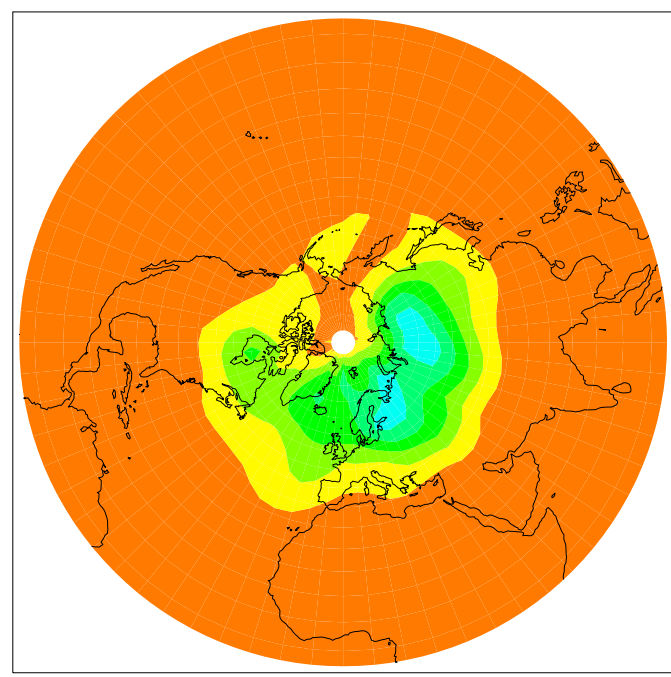

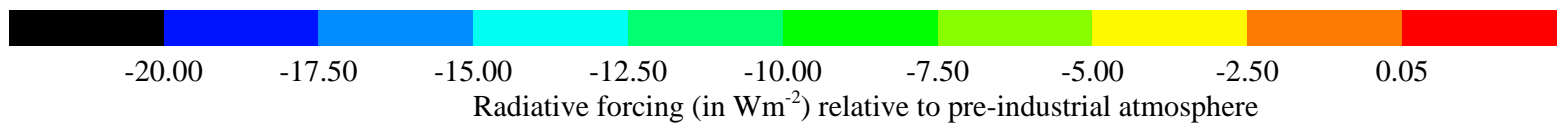

Fig. 3. Radiative forcing distribution (in $\mathrm{Wm}^{-2}$ ) in Northern Hemisphere in July 1783 for (a) "Hi” and (b) "Lo" simulations.

forcing due to the explosive eruption of Mt. Pinatubo reached around $-4 \mathrm{Wm}^{-2}$ but persisted for around two years. The simulations therefore give quite a large magnitude global mean forcing for an eruption that only affected the lower atmosphere (lower than $15 \mathrm{~km}$ ), but this forcing lasted for only a short time. The Northern Hemisphere mean forcing peaks at almost $-6 \mathrm{Wm}^{-2}$ in August under the "Hi" Scenario, roughly twice that in the "Lo" scenario. Under the "Lo" scenario there is negligible forcing in the Southern Hemisphere, while under the "Hi" scenario there is a small peak in January 1784. This indicates that there is some long range transport of aerosol under the "Hi" scenario which reaches the southern hemisphere and then produces a maximum in forcing when the hemispheric insolation is a maximum. This is consistent with both the evidence that the forcing due to Laki was predominantly a Northern Hemisphere phenomenon (no signal being observed in Southern Hemisphere ice cores) and the expectation that aerosol from high latitude eruptions is not transported significantly into the opposite hemisphere (Robock, 2000). The two "Hi" scenarios differ slightly in years two and three reflecting the different residence time of the aerosol, however, in all cases the forcing dies away rapidly once the eruption has finished.

The latitudinal extent of radiative forcing is shown in Fig. 2, confirming that the radiative forcing is largely confined to the northern hemisphere in all three cases. In the "Hi" scenarios the maximum occurring between 55 and $70^{\circ} \mathrm{N}$ extends into August and September 1783, while in the "Lo" scenario the peak zonal mean forcing is more re- stricted to July and August. The relative maximum in the tropics during the winter following the eruption is also more clearly seen in this figure. In both "Hi" scenarios small negative forcing amounts (of the order $-0.5 \mathrm{Wm}^{-2}$ ) extend in the midlatitudes of both hemispheres well into 1785 .

Figure 3 shows the geographical distribution of the ensemble mean direct radiative forcing due to Laki aerosol relative to a "clean" pre-industrial atmosphere calculated for the peak forcing month of July 1783, for "Hi" (Fig. 3a) and "Lo" (Fig. 3b) scenarios. We present only plots for the Northern Hemisphere since Figs. 1 and 2 show the Southern Hemisphere forcing to be small. The largest forcings are not surprisingly in regions close to and downwind of the eruption over North-western Europe and Greenland. The peak radiative forcing reaches in excess of $-17.5 \mathrm{Wm}^{-2}$ (in the "Hi" scenario). Considerable negative forcings of greater magnitude than $2.5 \mathrm{Wm}^{-2}$ cover extensive parts of the Northern Hemisphere throughout June-September 1783. Most of the direct radiative forcing of aerosols shown here is due to the impact of aerosols on shortwave radiation. The peak magnitude of the longwave effect was only a few percent of the total direct forcing and of the opposite sign.

In summary, the sulphate aerosol from the simulations of the Laki eruption produced a large negative radiative forcing in the Northern Hemisphere through the scattering of solar radiation to space which peaked in July to September, depending on the emission scenario considered. The forcing was considerably stronger for the "Hi" cases due to both an increase in total column burden in this simulation and the 
Table 1. Northern hemisphere and annual mean surface temperature anomalies for Laki simulations compared to a "clean" pre-industrial atmosphere

\begin{tabular}{cccc}
\hline Year & "Lo" & "Hi/short" & "Hi/Long" \\
\hline 1783 & -0.01 & -0.21 & -0.21 \\
1784 & +0.01 & -0.17 & -0.19 \\
1785 & -0.08 & -0.12 & -0.14 \\
\hline
\end{tabular}

higher altitude of the aerosol. For the "Hi" scenarios, the forcing persisted, albeit much reduced, into 1785 in the midlatitudes of both hemispheres.

\subsection{Surface temperature changes}

We now calculate the climate response to the direct forcing caused by the Laki sulphate aerosol. We concentrate mainly on changes in surface temperature since this is the only climatic variable of which we have observations at this time. Additionally, we concentrate mainly on hemispheric and global means since the IGCM has been run at relatively low horizontal resolution and is therefore not expected to capture variations on small spatial scales.

Figure 4 shows the ensemble mean, global and hemispheric mean temperature anomalies due to the Laki aerosol for each simulation, along with an indication of the months for which a non-directional student t-test shows significance at the $95 \%$ level. In all three quantities, the "Lo" simulation produces little consistency in temperature anomaly even during the times when peak forcing was occuring. The "Hi" simulations however do show significant cold anomalies in the Northern Hemisphere and global mean temperatures throughout 1783 and 1784. Peak Northern Hemisphere mean cold anomalies reach $-0.35 \mathrm{~K}$ during August to November 1784 and the global mean anomaly reaches $-0.2 \mathrm{~K}$ during the same period. These results demonstrate that the temperature effect due to direct radiative forcing from the sulphate aerosol from Laki would mainly occur in the Northern Hemisphere, consistent with the lack of a temperature signal for Laki in Southern Hemisphere ice cores. Assuming negligible difference between the pre-industrial and Laki runs in the months before the eruption in 1783, the Northern Hemisphere mean temperature anomaly for 1783 as a whole is $-0.21 \mathrm{~K}$, while the global mean temperature anomaly is $-0.13 \mathrm{~K}$ for the same period. The Northern Hemisphere ensemble and geographic mean anomalies for each simulation and each year are shown in Table 1.

The Northern Hemisphere mean calculated using the Laki "Hi" simulation for 1783 is in reasonable agreement with observations of $-0.14 \mathrm{~K}$ (Angell and Korshover, 1985) and $-0.27 \mathrm{~K}( \pm 0.3 \mathrm{~K})$ (Briffa et al., 1998). Our simulations suggest that this cold anomaly could have persisted for at least two years after the eruption.
Although we are aware of the limitations of the IGCM, and climate models in general, in reproducing regional scale climate anomalies, the temperature response due to the Laki aerosols is highly spatially variable. Figure 5 shows seasonally averaged temperature anomalies in the "Hi/Long" simulation in order to compare with reports of "warm summers" and "cold winters". The coldest temperature anomalies occur over Greenland and other high latitudes during SeptemberOctober-November (SON) 1783. Greenland and Northern Canada remain cold throughout the winter but there is evidence of a $1.5 \mathrm{~K}$ warming over Scandinavia in later seasons. The Middle East persistently suffers cold anomalies until March-April-May (MAM) 1785, perhaps consistent with reports of famine there (Stothers, 1996). Alaska appears to generally experience anomalies of up to $-1 \mathrm{~K}$ during JJA 1783 which may be consistent with Jacoby and D'Arrigo (1999) although there is no indication of the $-4 \mathrm{~K}$ anomalies reported by that study. Interestingly there is no indication of positive temperature anomalies over Western Europe during the summer of 1783. The observations of warm summers are generally believed to be a result of anomalous southerly flow bringing western Europe under the influence of warm tropical airmasses (Thordarson and Self, 2002). This simulation does not produce such a pattern in response to aerosol direct forcing, suggesting that the existence of such a pattern may have been either due to one of the volcanic influences neglected in this simulation (see the following section for more discussion), independent of the volcanic forcing, or a limitation of the relatively low horizontal resolution of the models employed.

It is important to note however, that the statistical significance of these spatially variable differences is generally small since the Northern Hemisphere climate is very variable during Northern Hemisphere winter. Only a few regions in some seasons reach $95 \%$ significance. Due to the relatively coarse horizontal resolution of the IGCM and the use of 1980 meteorology rather than the meteorology of 1783/84 in the chemical transport model, any discussion of potential circulation changes or mechanisms which could bring about the observed and modelled temperature changes is somewhat premature. There was no significant change in hemispheric or global mean cloud cover or precipitation. Statistically significant (95\% level) increases in the Northern Hemisphere surface albedo were produced during the 1 st year of the "Hi" simulations, while the mean snowdepth was increased in these simulations during December-January-February (DJF) $1783 / 84$. There was no significant change in mean sea level pressure across the Northern Hemisphere.

The results of these simulations should be viewed as a first attempt to simulate the climate response to such an eruption. Ideally a consistent ensemble of simulations of the chemical transport model and climate model would test the robustness of our results, particularly the spatial pattern of forcing and response. It may also be possible to use some observations of surface pressure over Europe and the USA to constrain 

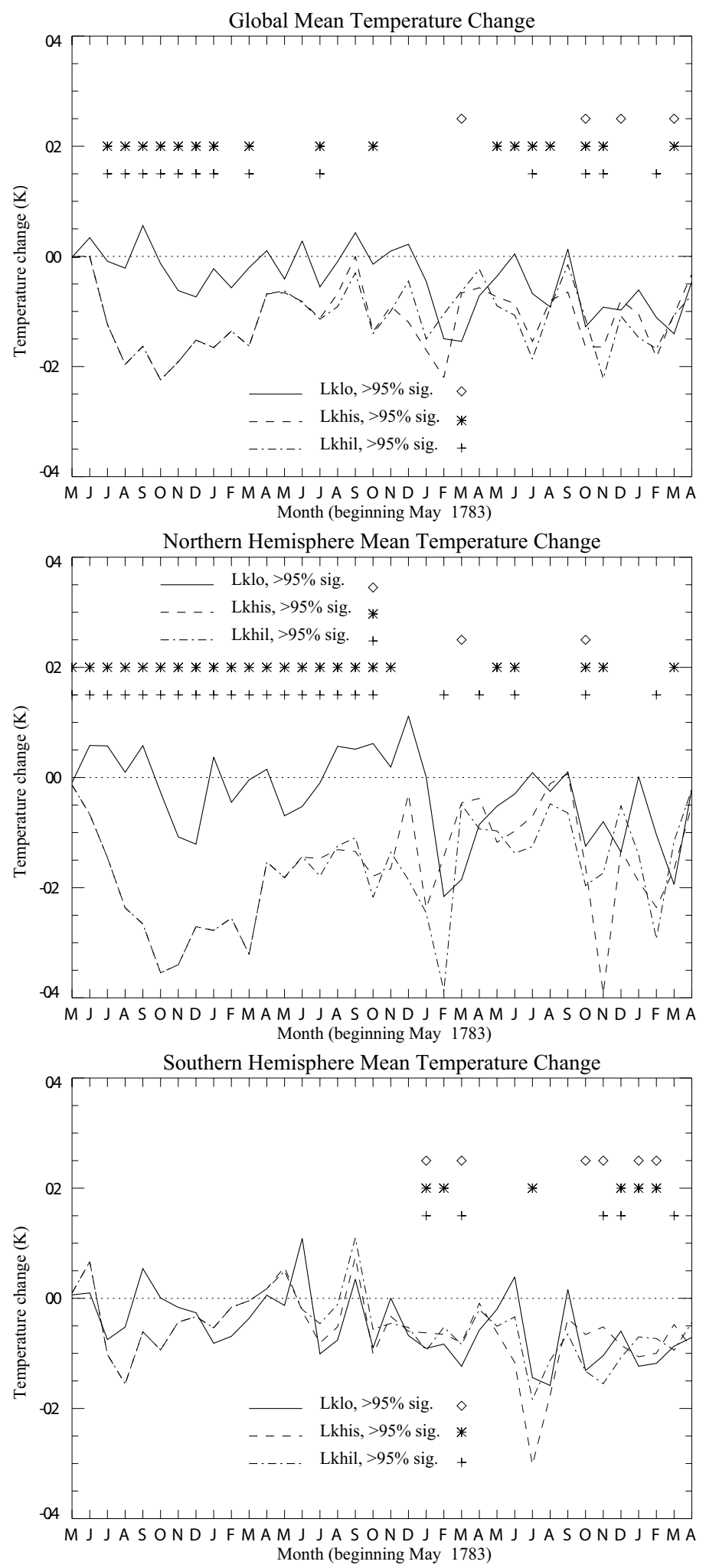

Fig. 4. Temporal evolution of ensemble mean surface temperature anomaly (in K) relative to simulations with pre-industrial atmosphere. Panel A: Global mean, Panel B: Northern Hemisphere mean, Panel C: Southern hemisphere mean. Solid line is "Lo" simulation, dashed line is "Hi/short" simulation, dot-dashed line is "Hi/long" simulation. Symbols above the curves denote the months where the difference in temperature is statistically different at the $95 \%$ level from that using the pre-industrial atmosphere. 
a) JJA 1783

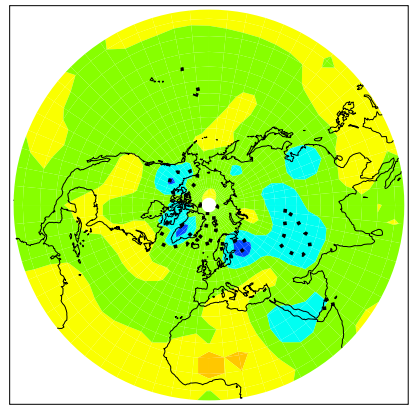

c) DJF $1783 / 84$

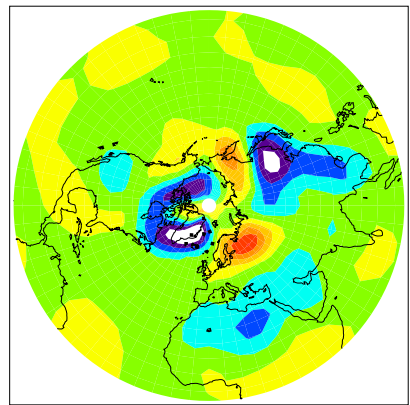

e) JJA 1784

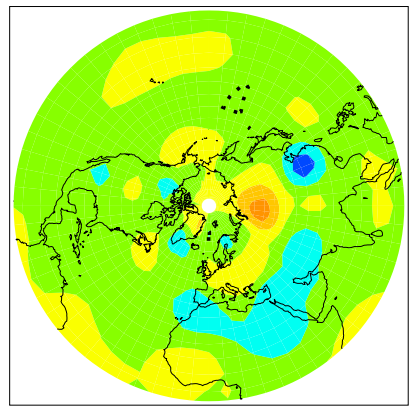

g) DJF $1784 / 85$

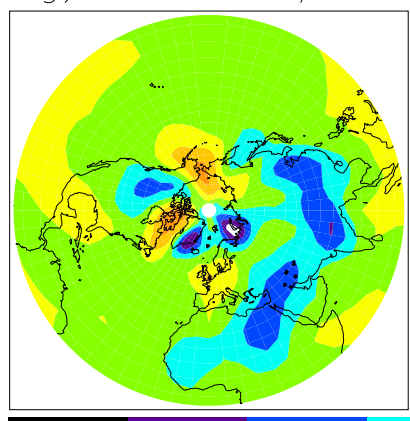

b) SON 1783

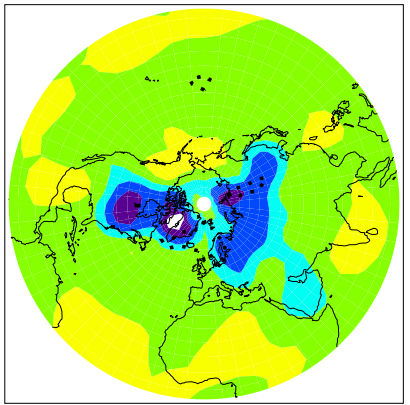

d) MAM 1784

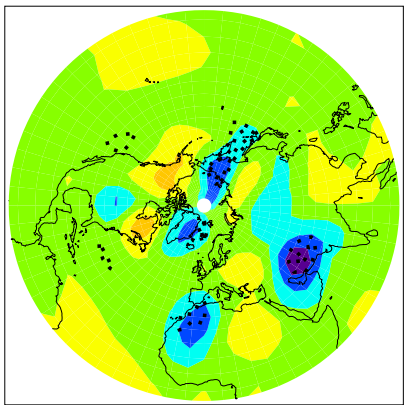

) SON 1784

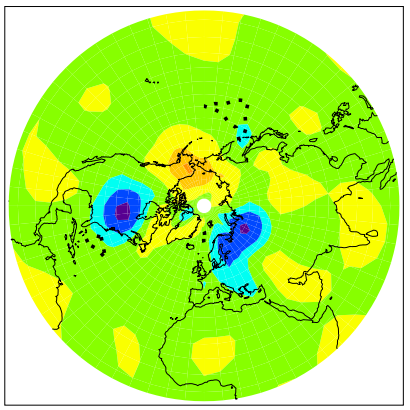

h) MAM 1785

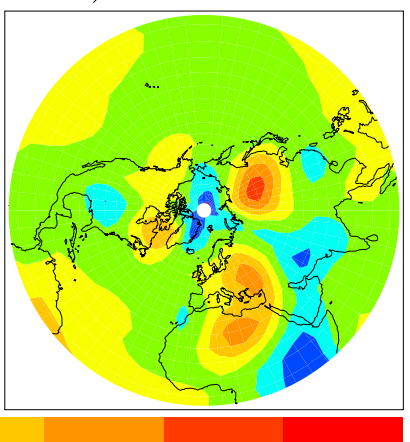

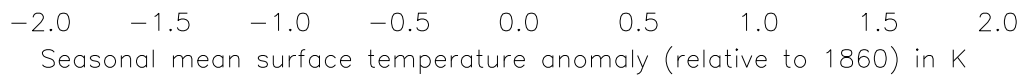

Fig. 5. Seasonally averaged ensemble mean surface temperature anomaly relative to pre-industrial simulation for the Laki "Hi/Long" simulation, June-July-August (JJA) 1783 (a) to March-April-May (MAM) 1785 (h). White contours show regions where the ensemble mean temperature is statistically different at the $95 \%$ level from that in the pre-industrial simulation. 
Table 2. Ratio of July 1783 Northern Hemisphere mean radiative forcing for sensitivity studies compared to that of the "Hi" base case with dry sulphuric acid, 2 wavelength band, 2 stream calculation of the IGCM. Base case value is $-5.5 \mathrm{Wm}^{-2}$.

\begin{tabular}{cc}
\hline Case & Forcing ratio \\
\hline Base & 1.0 \\
80\% relative humidity & 2.6 \\
4 stream & 1.01 \\
24 band & 0.62 \\
Ammonium sulphate & 0.004
\end{tabular}

the meteorology used in STOCHEM-Ed and the IGCM, or to use a fully coupled chemistry-climate model. However, this is beyond the capabilities of the present study.

\section{Uncertainties}

The uncertainties in the magnitude of $\mathrm{SO}_{2}$ emission, eruption height and chemistry have been extensively discussed in STE03 (Sect. 4.7). In this study we restrict our discussion of uncertainties to those arising from our treatment of the direct radiative forcing, our neglect of additional possible forcings and the limitations of climate modelling in general.

\subsection{Direct effect}

The direct radiative forcing has been calculated using the radiative transfer scheme of the IGCM for consistency with the climate response results. Necessarily, this scheme is simplified. The number of radiation bands used is restricted and only a 2-stream calculation is used. In addition we have made assumptions about the aerosol itself. To quantify the likely effect of these assumptions on our radiative forcing results, we have used a more sophisticated and flexible radiation code than is present in the IGCM. The radiative transfer model used is a discrete-ordinate model (Stamnes et al., 1988). Here we use it in configurations with a varying number of spectral bands, the absorption data for ozone and water vapour coming from exponential sum fit techniques similar to those used in Edwards and Slingo (1996). It is used to calculate forcing in clear skies. The forcing in cloudy skies due to sulphates is assumed negligible (Haywood and Shine, 1995) and the forcing at each point is then scaled by ( 1 - cloud fraction) from the IGCM climatology. Table 2 gives the ratio of radiative forcing compared to the base case scenario, for various sensitivity tests for July 1783, when aerosol loading peaked.

In the base case we have assumed that the sulphate aerosol at all altitudes is dry. If instead we assume that it has passed through regions where the relative humidity is $80 \%$, the direct forcing is approximately 2.6 times that found in the base case due to growth and increased scattering of the aerosol. 2-stream radiation codes such as that in the IGCM are sometimes considered inadequate to use in aerosol forcing calculations since they do not allow for a good representation of the aerosol phase function. Myhre et al. (1998) demonstrated that using a 2 stream code could introduce a difference of as much as $20 \%$. The intercomparison project of Boucher et al. (1998) suggests that 4 stream models agree reasonably well with higher order versions. The Laki forcing was recalculated using a 4 stream version of the radiative transfer model, but the averaged forcing is less than $1 \%$ different from the 2 stream calculation. Most of these differences occur at high latitudes.

The shortwave radiation scheme used in the IGCM has only 2 wavelength bands. This can introduce errors in the aerosol optical properties which must be averaged over quite large wavebands. Table 2 shows that increasing to a 24 band solar scheme, the forcing is reduced by around $40 \%$, suggesting that the IGCM forcing may in fact be too large.

The forcing due to changes in ammonium sulphate has also been calculated assuming the same tropospheric aerosol size distribution and humidity. However, in the preindustrial atmosphere there are very few spare ammonium ions (Stevenson et al., 2003) and so the $\mathrm{SO}_{2}$ from the eruption mainly forms sulphuric acid rather than ammonium sulphate. The spatially averaged forcings are a few hundredths of that due to the changes in sulphuric acid. The spatial patterns of forcing due to ammonium sulphate are slightly different, with local peaks in forcing over South America and southern Africa (spare ammonium ions from biomass burning). Only over South America does the ammonium sulphate forcing reach $10 \%$ of the sulphuric acid forcing, which is in any case very small in this region.

The combination of these effect suggests that the true direct radiative forcing due to sulphate aerosol from the Laki simulations could be up to 1.6 times (60\% of the factor 2.6 ) that calculated in this study (without considering the uncertainties inherent in the production of the sulphate aerosol field themselves as discussed in STE03).

\subsection{Indirect effects}

We have not addressed the indirect effects of the sulphate aerosol produced on cloud microphysics. The so-called first indirect effect, whereby the presence of aerosols increases the number of small droplets thereby increasing the albedo of the cloud, would produce a potentially large additional negative radiative forcing, with a pattern somewhat different to the direct forcing. Representation of the indirect effects within the IGCM would be premature given the large uncertainties in the indirect effects of aerosols in general (Intergovernmental Panel on Climate Change, 2001) and the relatively coarse horizontal resolution of the simulations. However, a test calculation using the aerosol distributions for July 1783 and empirical relationships between sulphate mass, aerosol number and cloud droplet effective 
radii (Boucher and Lohmann, 1995; Slingo and Schrecker, 1981) and following the methodology of Intergovernmental Panel on Climate Change (2001), suggests that an indirect effect on cloud could result in an additional Northern Hemisphere mean forcing of between $-8 \mathrm{Wm}^{-2}$ ("Lo" scenario) and $-14 \mathrm{Wm}^{-2}$, ("Hi" scenario) i.e. considerably more than the size of the direct effect calculated here. The spatial pattern of the indirect effect was different to that of the direct forcing, peaks occuring over the Atlantic and Pacific Oceans, in common with estimates of the indirect effect due to industrial sulphates (Intergovernmental Panel on Climate Change, 2001). A further complication when considering the likely impact of the indirect effect is that in the "Hi" scenarios, much of the aerosol is in the upper troposphere and lower stratosphere. While Jensen and Toon (1992) and Karcher and Lohmann (2002) do consider the indirect of volcanic aerosols on climate, almost all work on the indirect effect to date has examined the effect of aerosol on low altitude clouds. The interaction of aerosol with higher altitude clouds, particularly mixed phase clouds, and the role of aerosol as ice nuclei is extremely uncertain (Intergovernmental Panel on Climate Change, 2001). Indeed, Luo et al. (2002) found no evidence of any cloud changes in satellite observations following the Pinatubo eruption, and Lohmann et al. (2003) found significant changes in cloud properties only when very large amounts of sulphate aerosol were used. The indirect effects of aerosols from the Laki eruption are potentially large, but impossible to quantify with any confidence at this moment in time.

\subsection{Other possible radiative forcing agents}

We have not yet addressed the possible effect on climate of changes in ozone resulting from changes in the tropospheric chemistry after the eruption. The changes observed in Stevenson et al. (2003) suggest a likely small positive forcing due to increased tropospheric ozone polewards of $70^{\circ} \mathrm{N}$ and a small negative forcing due to decreases in the tropics.

Sulphur dioxide is itself a greenhouse gas. To test whether the vast amounts produced in the region of the volcano could have produced a significant positive radiative forcing, the Narrow Band Radiation Model of Shine (1991) was used together with a global mean atmospheric profile of other radiatively important gases. For an increase of 1 ppbv sulphur dioxide throughout the atmospheric column, the radiative forcing was $0.02 \mathrm{Wm}^{-2}$. For the peak zonal mean sulphur dioxide concentrations of $20 \mathrm{ppbv}$, this amounts to only $0.4 \mathrm{Wm}^{-2}$, which is less than $10 \%$ of the large negative direct radiative forcing from the sulphate aerosols. There would also have been substantial amounts of tephra and ash in the eruptions which fall out of the atmosphere more rapidly than the smaller sulphate aerosols. At present, this aerosol is not included, but may have modulated the forcing values close to the volcano itself.

\subsection{Climate sensitivity}

The magnitude of the temperature response of a model to an imposed radiative forcing will depend strongly on the model itself. Model intercomparisons show that the climate sensitivity parameter, $\lambda$, defined for an equilibrium global mean temperature change, $\Delta T$, using: $\Delta T=\lambda \Delta F$ where $\Delta F$ is the global mean radiative forcing, varies between GCMs from 0.5 to $1.2 \mathrm{~K}\left(\mathrm{Wm}^{-2}\right)^{-1}$ (Intergovernmental Panel on Climate Change, 2001). The climate sensitivity parameter for this version of the IGCM (calculated using a doubling of $\left.\mathrm{CO}_{2}\right)$ is $0.6 \mathrm{~K}\left(\mathrm{Wm}^{-2}\right)^{-1}$, placing it at the low end of the range of models. A model with a higher climate sensitivity parameter would tend to predict a higher equilibrium surface temperature response to a given forcing. However, with a short duration forcing such as that due to the Laki aerosol, experiments with an energy balance model (e.g. Shine and Highwood, 2002) suggest that the peak global mean temperature change would be very similar for all values of $\lambda$ within the Intergovernmental Panel on Climate Change (2001) range. The duration of the global mean temperature perturbation however would be approximately twice as long for $\lambda=1.2 \mathrm{~K}\left(\mathrm{Wm}^{-2}\right)^{-1}$ than for a model having $\lambda=0.6 \mathrm{~K}\left(\mathrm{Wm}^{-2}\right)^{-1}$. Thus, in so far as an energy balance model is a good indication of the behaviour of GCMs, the duration of the temperature response of the IGCM to Laki is likely to be a lower limit. A longer duration response might be consistent with observations of cold winters during subsequent years, although there is no obvious evidence of a prolonged period of cold temperatures (e.g. Briffa et al., 1994).

\section{Conclusions}

This study has presented the first climate model simulation of some potential effects of an eruption like that of Laki in 1783-1784. Substantial amounts of sulphuric acid aerosols produced a large negative radiative forcing over much of the Northern Hemisphere during June 1783 to Feburary 1784. The Northern Hemisphere mean forcing peaked at $-5.5 \mathrm{Wm}^{-2}$. Sensitivity tests show that this could be an underestimate and that the real direct effect could be 1.6 times larger, mainly due to the assumptions about relative humidity effects on the aerosol scattering properties. Indirect effects on cloud microphysics are potentially large but impossible to quantify reliably.

The direct radiative effect of Laki aerosol affected the climate of the Northern Hemisphere in the IGCM at least throughout 1783 and 1784 in the simulations using the aerosol distribution from the "Hi" altitude $\mathrm{SO}_{2}$ emission scenario. Northern Hemisphere mean temperature anomalies for $1783(-0.21 \mathrm{~K})$ due to the direct effect of aerosols calculated using the IGCM are in reasonable agreement with the somewhat limited observations after the 1783-1784 eruption and 
are significant at the $95 \%$ level. The temperature response is spatially complex.

Any mechanisms or circulation changes by which the temperature response occurs remain to be determined, ideally in a GCM with higher horizontal resolution. No significant changes in cloud cover or surface pressure patterns were diagnosed from the IGCM simulations. Northern Hemisphere mean snow depth did increase during the winter following the eruption. Ideally, an ensemble of runs of the chemical transport model and the IGCM should be performed, or observations of surface pressure from that time period assimilated in some way to ensure the correct distribution of eruption material and the resulting aerosol through the Northern Hemisphere.

It is interesting that, given the likelihood that our estimate of negative radiative forcing is somewhat smaller than reality (as discussed in Sect. 5), we obtain a Northern Hemisphere mean temperature response that is within the range of the observational estimates when considering the "Hi" scenarios. If the observations are to be believed, and the indirect effects of the aerosol on clouds were to produce a large negative forcing, simulated temperature anomalies could be considerably larger than the observations. In that case there would need to be some mechanism decreasing the cold anomaly in the Northern Hemisphere, perhaps a widespread and persistent anomalous circulation pattern independent of the volcanic effects? Alternatively, the aerosol resulting from the "Lo" scenario, together with large indirect effects could also produce a temperature anomaly in agreement with observations.

Despite the uncertainties detailed above and in Sect. 5, this study has shown that large and long duration eruptions such as Laki, producing aerosol mainly in the troposphere, can have a significant effect on climate on at least hemispheric and seasonal scales through the formation of large-scale tropospheric aerosol clouds that cause a large and widespread negative radiative forcing. Such eruptions are not restricted to history, nor to Iceland. As such, this study represents a starting point for future simulations of the atmospheric and climatic impact of these eruptions. It also highlights the areas where more knowledge is needed in order to allow us to confirm or deny the suggestion of Franklin (1785) regarding the Laki eruption and its impact on climate.

Acknowledgements. EJH was funded in part through a personal NERC postdoctoral fellowship (GT5/98/3/AS). DSS was funded by a NERC/Environment Agency fellowship (P4-F02). M. Joshi is thanked for developmental work on the IGCM. K. Shine is thanked for comments on an early version of this manuscript.

\section{References}

Angell, J. and Korshover, J.: Surface temperature changes following the six major volcanic episodes between 1780 and 1980, J. Clim. Appl. Meteorol., 24, 937-951, 1985.

Boucher, O. and Lohmann, U.: The sulfate-ccn-cloud albedo effect, Tellus, 47B, 281-300, 1995.

Boucher, O., Schwartz, S., Ackerman, T., Anderson, T., Bergstrom, B., Bonnnel, B., Chylek, P., Dahlback, A., Fouquart, Y., Fu, Q., Halthore, R., Haywood, J., Iversen, T., Kato, S., Kinne, S., Kirkevag, A., Knapp, K., Lacis, A., Laszlo, I., M.I.Mishchenko, Nemesure, S., Ramaswamy, V., Roberts, D., Russell, O., Schlesinger, M., Stephens, G., Wagener, R., Wang, M., Wong, J., and Yang, F.: Intercomparison of models representing direct shortwave radiative forcing by sulfate aerosols, J. Geophys. Res., 16979-16998, 1998.

Briffa, K., Jones, P., and Schweingruber, F.: Summer temperatures across northern north america: Regional reconstructions from 1760 using tree ring densities., J. Geophys. Res., 99, 25835 $25844,1994$.

Briffa, K., Jones, P., Schweingruber, F., and Osborn, T.: Influence of volcanic eruptions on northern hemisphere summer temperature over the past 600 years, Nature, 393, 450-454, 1998.

Durand, M. and Grattan, J.: Extensive respiratory health effects of volcanogenic dry fog in 1783 inferred from european documentary sources, Env. Geochem. and Health, 21, 371-376, 1999.

Edwards, J. and Slingo, A.: Studies with a flexible new radiation code. i. choosing a configuration for a large-scale model, Quart. Jour. Roy. Met. Soc., 122, 689-719, 1996.

Fiacco, R., Thordarson, T., Germani, M., Self, S., Palais, J., Whitlow, S., and Grootes, P.: Atmospheric aerosol loading and transport due to the 1783-84 laki eruption in iceland, interpreted from ash particles and acidity in the gisp2 ice core, Quaternary Research, 42, 231-240, 1994.

Fisher, D. and Koerner, R.: Some aspects of climatic changes in the high arctic during the holocene as deduced from ice cores, in Quaternary Paleoclimate, edited by W. Maheney, Geology Abstracts, 249-271, Norwich, 1981.

Forster, P., Blackburn, M., Glover, R., and Shine, K.: An examination of climate sensitivity for idealised climate change experiments in an intermediate general circulation model, Clim. Dyn., 16, 833-849, 2000.

Franklin, B.: Meteorological imaginations and conjectures, Mem. Lit. Phil. Soc. Manchester, 2, 357-361, 1785.

Fujii, Y., Kamiyama, K., Kawamura, T., Izumi, K., Satow, K., Enomoto, H., Nakamura, T., Hagen, J., Gjessing, Y., and Watanabe, O.: 6000-year climate records in and ice core from the Hoeghetta ice dome in northern Spitsbergen, Ann. Glaciol., 14, 85-89, 1990.

Graf, H.-F., Feichter, J., and Langmann, B.: Volcanic sulfur emissions: Estimates of source strength and it's contribution to the global sulfate distribution, J. Geophys. Res., 102, 10 727-10 738, 1997.

Grainger, R. and Highwood, E.: Changes in stratospheric composition, chemistry, radiation and climate caused by volcanic eruptions, in Volcanic Degassing, Oppenheimer, C., Pyle, D. M., and Barclay, J. (Eds), Geological Society Special Pub. 213, Geological Society, Bath, UK, 2003. 
Grattan, J. and Pyatt, F.: Volcanic eruptions dry fogs and the european palaeoenvironmental record: localised phenomena or hemispheric impacts?, Global and Planetary Change, 21, 173-179, 1999.

Hammer, C.: Past volcanism revealed by Greenland ice sheet impurities, Nature, 270, 482-286, 1977.

Haywood, J. and Shine, K.: The effect of anthropogenic sulfate and soot aerosol on the clear sky planetary radiation budget, Geophys. Res. Lett., 603-606, 1995.

Hoskins, B. and Simmons, A.: A multi-layer spectral model and the semi-implicit method, Quart. Jour. Roy. Met. Soc., 101, 637, 1975.

Intergovernmental Panel on Climate Change: Climate Change 1995: the Science of climate change, Cambridge University Press, 1995.

Intergovernmental Panel on Climate Change: Climate Change 2001: The Scientific Basis, Cambridge University Press, 2001.

Jacoby, G. C. , K. W. and D'Arrigo, R.: Laki eruption of 1783, tree rings, and disaster for northwest alaska inuit, Quaternary Science Reviews, 18, 1365-1371, 1999.

Jager, H. and Carnuth, W.: The decay of the El-Chichon stratospheric perturbation, observed by lidar at northern mid-latitudes, Geophys. Res. Lett., 14, 696-699, 1987.

Jensen, E.J. and Toon, O.B.: The potential effects of volcanic aerosols on cirrus cloud microphysics, Geophys. Res. Letts., 19, 1759-1762, 1992.

Karcher, B. and Lohmann, U.: A parameterization of cirrsu cloud formation: Homogenouse freezing including the effects of aerosol size, J. Geophys. Res. 107, 10.1029/2001JD001429, 2002.

Kent, G. and Hansen, G.: Multiwavelength lidar observations of the decay phase of the stratospheric aerosol layer produced by the eruption of Mt. Pinatubo in June 1991, Applied Optics, 37, 3861-3872, 1997.

Kiehl, J. and Briegleb, B.: The relative roles of sulfate aerosols and greenhouse gases in climate forcing, Science, 260, 311-314, 1983.

Kohno, M., Kusakabe, M., Yamaguchi, Y., and Machida, H.: Estimation of sulfur and chlorine yields to the atmosphere by historic vocanic eruptions in Japan: A petrologic approach based on glass inculdsion analysis, Paper presented at IGBP PAGES - INQUA COT Meeting, 1993.

Li, D. and Shine, K.: A three dimensional ozone climatology for use in general circulation models, Tech. Rep. 14, UGAMP University of Reading, 1995.

Lohmann, U., Karcher, B, and Timmreck, C.: Impact of the Mt. Pinatubo eruption on cirrus clouds formed by homogeneous freezing in the ECHAM GCM, Institute fir Physik der Atmosphare, Report No. 1902003.

Luo, Z., Rossow, W. B., Inoue, T., and Stubenrauch, C. J.: Did the eruption of the Mt. Pinatubo volcano affect cirrus properties?, J. Climate, 15, 2806-2820, 2002.

Mikami, T.: Climate of Japan during 1781-1790 in comparison with that of China, China Ocean Press, Beijing, 1987.
Minnis, P., Harrison, E., Stowe, L., Gibson, G., Denn, F., Doelling, D., and Smith, W.: Radiative climate forcing by the Mount Pinatubo eruption, Science, 259, 1411-1415, 1993.

Morcrette, J.: Impact of changes to the radiative transfer parameterisations plus cloud optical properties in the ECMWF model, Mon. Wea. Rev., 118, 847-873, 1990.

Myhre, G., Stordal, F., Restad, K., and Isaksen, I.: Estimation of the direct radiative forcing due to sulfate and soot aerosols, Tellus Series B - Chemical and Physical Meteorology, 50, 463-477, 1998.

Renovantz, H.: Mineralogisch-Geographische und andere vermischte Nachrichten von den Altaischem Geburgen, Russich Keyserlichen Anteils, Imperial Academy of Sciences, 1788.

Robock, A.: Volcanic eruptions and climate, Reviews of Geophysics, 38, 191-219, 2000.

Shine, K.: On the cause of relative greenhouse strength of gases such as the halocarbon, J. Atmos. Sci., 12, 1513-1518, 1991.

Shine, K. and Highwood, E.: Problems in quantifying natural and anthropogenic perturbations to the earth's energy balance, in Meteorology at the Millennium, edited by R. Pearce, vol. 83 of International Geophysics Series, 2002.

Sigurdsson, H.: Volcanic pollution and climate: the 1783 laki eruption, EOS, 63, 601-602, 1982.

Slingo, A. and Schrecker, H.: On the shortwave radiative properties of stratiform water clouds, Quart. Jour. Roy. Met. Soc., 108, 407426, 1981.

Stamnes, K., Tsay, S.-C., Wiscombe, W., and Jayweera, K.: A numerically stable algorithm for discrete ordinate method radiative transfer in multiple scattering and emitting layered media, Appl. Opt., 27, 2502-2509, 1988.

Stenchikov, G., Kirchner, I., Robock, A., Graf, H., Antuna, J., Grainger, R., Lambert, A., and Thomason, L.: Radiative forcing from the 1991 Mount Pinatubo volcanic eruption, Jour. Geophys. Res., 103, 13 837-13 857, 1998.

Stevenson, D., Johnson, C., Highwood, E., Gauci, V., Collins, W., and Derwent, R.: Atmospheric impact of the 1783-1784 Laki eruption : Part I chemistry modelling, Atmos. Chem. Phys. Discuss., 3, 551-596, 2003.

Stothers, R.: The great dry fog of 1783, Climatic change, 32, 79-89, 1996.

Stothers, R.: Volcanic dry fogs, climate cooling and plague pandemics in europe and the middle east, Climatic change, 42, 713723, 1999.

Thordarson, T. and Self, S.: Atmospheric and environmental effects of the 1783-84 laki eruption; a review and reassessment, J. Geophys. Res., 2002.

WCP: A preliminary cloudless standard atmosphere for radiation computation, World Meteorological Organisation, 1986.

Wood, C.: Climatic effects of the 1783 Laki eruption, in "The Year without a Summer", Canadian Museum of Nature, 58-77, 1992.

Zielinski, W., Fiacco, R., Mayeski, P., L.D. Meeker, S. W., Twickler, M., Germani, M., Endo, K., and Yasui, M.: Climatic impact of the A.D. 1783 Asama (Japan) eruption was minimal: evidence from the gisp2 ice core, Geophys. Res. Lett., 21, 2365-2368, 1994. 